\title{
Keefektifan Metode Everyone is Teacher Here pada Materi Operasi Hitung Pecahan Kelas 4 Sekolah Dasar
}

\author{
Akhiudin Zakaria \\ SDIT Buah Hati \\ akhiudin03@gmail.com
}

\section{Article History}

received 3/12/2020

revised $17 / 12 / 2020$

accepted $31 / 12 / 2020$

\begin{abstract}
This research was motivated by the low learning outcomes of fractional operations in grade 4 SDIT Buah Hati. The cause of the problem is the use of conventional learning methods. This type of research is quantitative. Samples were taken randomly without regard to the existing strata in the population. The samples in this study were students in class $4 B$ with a total of 30 students as the experimental class and students in class $4 A$ with a total of 30 students as the control class using purpos 4 e random sampling technique. The research design used a pretestposttest control group design. The results of the calculation show that the average value of the experimental class is 85.87 while the average value of the control class is 74.27 . For the results of the t-test calculation with $d k=58$ and $=5 \%$, it is obtained that t_hitung 3,993 and t_table 1,671 So, the value of $t$ _count $>t$ table, then $\mathrm{HO}$ is rejected. After analyzing the hypothesis, it was concluded that the use of the everyone is teacher here method could improve the learning outcomes of fractional arithmetic operations for 4th grade students of SDIT Buah Hati.
\end{abstract}

Keywords: everyone is teacher here, fractional, elementary school

\begin{abstract}
Abstrak
Penelitian ini dilatarbelakangi rendahnya hasil belajar operasi hitung pecahan kelas 4 SDIT Buah Hati. Faktor penyebab dari permasalahan adalah penggunaan metode pembelajaran masih konvensional. Jenis penelitian ini adalah kuantitatif. Sampel diambil secara acak tanpa memperhatikan strata yang ada dalam populasi itu. Sampel dalam penelitian ini adalah siswa kelas 4B dengan jumlah 30 siswa sebagai kelas eksperimen dan siswa kelas 4A yang berjumlah 30 siswa sebagai kelas kontrol dengan menggunakan teknik purpos $4 \mathrm{e}$ random sampling. Desain penelitian menggunakan pretest-posttest control group design. Hasil perhitungan menunjukkan data nilai rata-rata kelas eksperimen 85,87 sedangkan nilai rata-rata nilai kelas kontrol 74,27. Untuk hasil perhitungan uji t dengan $\mathrm{dk}=58$ dan $\alpha=5 \%$ diperoleh t_hitung 3,993 dan t_tabel 1,671 Jadi, nilai t_hitung>t_tabel, maka H0 ditolak. Setelah melakukan analisis hipotesis disimpulkan bahwa penggunaan metode everyone is teacher here dapat meningkatkan hasil belajar operasi hitung pecahan siswa kelas 4 SDIT Buah Hati.
\end{abstract}

Kata kunci: everyone is teacher here, pecahan, sekolah dasar

Social, Humanities, and Education Studies (SHEs): Conference Series https://jurnal.uns.ac.id/shes

p-ISSN 2620-9284

e-ISSN 2620-9292

This work is licensed under a Creat4e Commons Attribution-ShareAlike 4.0 International License. 


\section{PENDAHULUAN}

Pendidikan adalah usaha sadar dan terencana untuk mewujudkan suasana belajar dan proses pembelajaran agar siswa secara aktif mengembangkan potensi dirinya untuk memiliki kekuatan spiritual keagamaan, pengendalian diri, kepribadian, kecerdasan, akhlak mulia, serta ketrampilan yang diperlukan dirinya, masyarakat, bangsa, dan negara dalam (Undang-Undang Sistem Pendidikan Nasional 2003, 2007:9-10).

Secara eksplisit fungsi pendidikan nasional sudah tercantum dalam UndangUndang No 20 tahun 2003 tentang Sistem Pendidikan Nasional dalam pasal 3 yakni, berfungsi untuk mengembangkan kemampuan dan membentuk watak serta peradaban bangsa yang bermartabat dalam rangka mencerdaskan kehidupan bangsa, bertujuan untuk berkembangnya potensi peserta didik agar menjadi manusia yang beriman dan bertakwa kepada Tuhan Yang Maha Esa, berakhlak mulia, sehat, berilmu, cakap, kreatif, mandiri, dan menjadi warga negara yang demokratis serta tanggung jawab.

Menurut Hardini (2011: 10), pembelajaran adalah proses membuat orang belajar. guru bertugas membantu orang belajar dengan cara memanipulasi lingkungan sehingga siswa dapat belajar dengan mudah, artinya guru harus bisa mengadakan pemilihan terhadap berbagai strategi pembelajaran yang ada, yang paling memungkinkan proses belajar siswa berlangsung optimal.

Pembelajaran matematika mengharuskan siswa untuk memahami banyak konsep mulai dari geometri, bilangan, sampai konsep aljabar. Di SD, konsep pecahan dan operasinya merupakan salah satu konsep yang penting untuk dikuasai siswa. Namun kenyataannya, siswa masih mengalami kesulitan dalam mempelajarinya seperti diungkapkan oleh Muhsetyo, dkk. (dalam Suryana, dkk., 2012, hlm.413) bahwa kenyataan di sekolah dasar menunjukkan masih banyak siswanya yang mengalami kesulitan dalam memahami pecahan dan operasinya. Beberapa guru menyatakan mengalami kesulitan dalam mengajarkan konsep pecahan.

Berdasarkan hasil observasi pembelajaran matematika materi operasi hitung pecahan di kelas 4 A dan 4 B di SDIT Buah Hati Pemalang, ditemukan beberapa siswa yang cenderung pasif dalam pembelajaran sehingga realitanya ketika pembelajaran berlangsung banyak ditemui siswa yang bermain sendiri dan tidak memperhatikan penyampaian materi dari guru, penyebabnya banyak salah satunya guru masih menggunakan pembelajaran yang konvensional, guru yang lebih aktif dalam pembelajaran.

Dari data yang diperoleh peneliti, didapat data bahwa dari 30 siswa yang terdiri dari 17 siswa perempuan dan 13 siswa laki - laki yang dapat mencapai Kriteria Ketuntasan Minimal (KKM) hanya 15 siswa (50\%), sedangkan 15 siswa (50\%) belum mencapai KKM. KKM yang ditentukan yaitu pada mata pelajaran Matematika 70. Sehingga dibutuhkan suatu metode atau model pembelajaran untuk meningkatkan hasil belajar siswa dalam proses belajar mengajar di kelas, khususnya di kelas 4 .

Metode pembelajaran Everyone is Teacher Here adalah metode pembelajaran yang memberikan suasana baru terhadap proses belajar mengajar. Karena metode ini menuntut siswa untuk belajar sendiri dan saling mengajari satu sama lain. Dengan menggunakan metode everyone is a teacher here dalam pembelajaran, siswa akan dilatih untuk bertanggung jawab dan meningkatkan kemampuan siswa dalam mengemukakan pendapat, menganalisis masalah dan keterampilan membuat simpulan. Setiap siswa diharapkan dapat menguasai suatu pokok bahasan tertentu sehingga dapat menjawab setiap pertanyaan yang didapatkanya.

Berdasarkan permasalahan peneliti ingin melakukan penelitian untuk menguji keefektifan penerapan metode pembelajaran Everyone Is Teacher Here pada materi operasi hitung pecahan kelas 4 SDIT Buah Hati Pemalang tahun ajaran 2020/2021. Oleh sebab itu, judul dalam penelitian ini adalah "Keefektifan Metode Everyone Is Teacher Here Pada Materi Operasi Hitung Pecahan Kelas 4 SDIT Buah Hati”. 


\section{METODE}

Penelitian dilaksanakan dari tanggal 10 Februari s/d 14 Februari 2020 di kelas 4 SDIT Buah Hati. Variabel terikat adalah hasil belajar siswa materi operasi hitung pecahan. Variabel bebasnya adalah metode Everyone Is Teacher Here. Peneliti mengambil sampel dari siswa kelas 4A dan kelas 4B.

Teknik sampling yang digunakan Probability Sampling yaitu Purpos4e random Sampling. "Purpos4e Random Sampling merupakan teknik pengambilan anggota sampel dari populasi dilakukan secara acak tanpa memperhatikan strata yang ada dalam populasi itu" (Sugiyono, 2012: 120). Dalam penelitian ini peneliti menggunakan desain/rancangan dengan tipe pretest-posttest control group design. Pengumpulan data menggunakan observasi dan tes.

Penggunaan instrumen diperlukan uji validitas, reliabilias, daya pembeda dan tingkat kesukaran pada setiap Validitas adalah suatu ukuran yang menunjukkan tingkat-tingkat kevalidan atau kesahihan sesuatu instrumen (Arikunto, 2010: 213). Uji validitas menggunakan rumus korelasi product moment. Butir soal hasil belajar menggunakan reliabilitas dengan teknik belah dua. Menghitung reliabilitas hasil belajar menggunakan rumus alpha. Menghitung reliabilitas pengamatan menggunakan rumus Fernandes dan Scout.

Tahapan dalam menganalisis data adalah melakukan analisis prasyarat dengan normalitas data awal. Perhitungan menggunakan hasil pre test siswa, Normalitas menggunakan uji Liliefors. Selanjutnya melakukan uji hipotesis yang meliputi uji normalitas dan uji t. dengan thitung $>$ ttabel, maka $\mathrm{HO}$ ditolak.

\section{HASIL DAN PEMBAHASAN}

Penelitian ini merupakan penelitian kelas eksperimen dan kelas kontrol untuk mengetahui adanya pengaruh sebuah metode pembelajaran. Kelas eksperimen adalah kelas yang diberikan perlakuan berupa pembelajaran Metode Everyone Is Teacher Here yang subjeknya adalah siswa kelas 4B dengan jumlah 30 siswa. Sedangkan kelas kontrol adalah kelas yang tidak diberikan perlakuan seperti kelas eksperimen melainkan hanya menggunakan pembelajaran yang biasa digunakan oleh guru (kurang variatif) yang subjeknya adalah siswa kelas $4 \mathrm{~A}$ yang berjumlah 30 siswa.

Pada pelaksanaan proses pembelajaran di SDIT Buah Hati Pemalang sebagai kelas kontrol yang menggunakan menggunakan pembelajaran konvensional (metode ceramah) yaitu kelas 4A, sedangkan sebagai kelas eksperimen adalah kelas 4B. Setelah dilaksanakan evaluasi di kedua kelas diperoleh hasil belajar siswa pada kelas kontrol lebih rendah daripada siswa kelas eksperimen. Hal tersebut dikarenakan pembelajaran di kelas kontrol berpusat pada guru, siswa hanya menerima informasi dari guru, siswa belum diberi kesempatan untuk terlibat langsung dalam pembelajaran, sehingga siswa kurang aktif dalam pembelajaran serta antusias dan minat siswa kurang karena siswa yang aktif kurang diarahkan untuk dikembangkan.

Pada siswa kelas 4B sebagai kelas eksperimen yang dalam pembelajarannya menerapkan metode Everyone Is Teacher Here, siswa yang selama ini tidak mau terlibat ikut serta dalam pembelajaran secara aktif, siswa secara aktif berpartisipasi secara keseluruhan maupun secara ind4idu dalam proses pembelajaran, setiap siswa mendapat kesempatan untuk berperan sebagai guru bagi teman-temannya, selain itu siswa juga aktif bertanya mengenai materi yang belum dipahami. Proses pembelajaran dengan menggunakan metode Everyone Is Teacher Here menjadikan suasana kelas menjadi semangat, meriah dan menyenangkan. Metode Everyone Is Teacher Here juga merupakan salah satu metode pembelajaran kooperatif yang bersifat menyenangkan dan meningkatkan kemampuan siswa dalam menyampaikan idea atau pendapatnya, menuliskan pendapatnya setelah melakukan pengamatan dan 
penyimpulan. selain itu siswa juga dapat saling belajar dan saling bertukar pikiran dengan bergantian menjadi guru dan siswa.

Pada penelitian yang dilakukan, saat pembelajaran yang berlangsung siswa yang kurang aktif baahkan siswa yang tidak pernah mendapat kesempatan untuk menyampaikan pendapatnya memiliki kesempatan untuk mengemukakan pendapat dan mengajukan pertanyaan. Bahkan siswa yang tidak pernah aktif akan memiliki kesempatan untuk bertanya dan menjawab pertanyaan. Karena metode everyone is teacher here ini membuat semua siswa mau tidak mau menuliskan pertanyaan mengenai materi yang baru sja disampaikan oleh guru. Siswa juga tidak memiliki kesempatan untuk bermain sendiri dan siswa sangat memperhatikan pelajaran yang disampaikan oleh guru karena setelah penyampaian materi siswa akan diberi waktu untuk membuat pertanyaan pada secarik kertas yang berkaitan dengan materi yang disampaikan. Guru bertindak sebagai fasilitator jika siswa mengalami kesulitan dalam membuat pertanyaan. Pertanyaan siswa yang telah terkumpul pada guru akan dibagikan kembali pada siswa namun bukan pertanyaan milik sendiri melainkan pertanyaan yang dibuat oleh teman. Siswa diberiklan waktu untuk menjawab pertanyaan tersebut. Ketika siswa membacakan pertanyaan yang didapat dan menjawab pertanyaan tersebut maka siswa yang lain menyimak. Apabila terdapat kesalahn dalam menjawab atau jawaban kurang tepat maka siswa yang lain dapat menambahkan atau membetulkan jawaban. Guru pun yang bertindak sebagai fisilitator akan membantu siswa yang mengalami kesulitan dalam menjawab pertanyaan dan membetulkan pertanyaan apabila kata-kata yang digunakan siswa kurang baik.

Penelitian ini sesuai pendapat Sodiq (2011: 21) Everyone Is Teacher Here merupakan metode yang dapat digunakan untuk meningkatkan proses pembelajaran siswa, dan dapat disesuaikan dengan tujuan yang ingin dicapai oleh pembelajaran pada berbagai mata pelajaran, khususnya mencapai tujuan yaitu meliputi aspek: kemampuan mengemukakan pendapat, kemampuan menganalisa masalah, kemampuan menuliskan pendapat-pendapatnya (kelompoknya) setelah melakukan pengamatan, kemampuan menyimpulkan, dan lain-lain.

Penelitian ini diawali dengan membuat soal uji coba dengan jumlah soal sebanyak 50 soal pilihan ganda disertai kisi-kisi soal. Dari soal uji coba yang telah diujikan selanjutnya dianalisis untuk mengetahui jumlah soal yang memenuhi kriteria valid, reliabel, taraf kesukaran, dan daya pembeda.

Nilai pre-test diambil sebelum pelaksanaan pembelajaran, baik pada kelas eksperimen maupun kelas kontrol. Nilai pre test diperoleh pada kelas eksperimen dan kontrol yang belum diberikan proses pembelajaran dengan menggunakan Metode Everyone Is Teacher Here yang diambil dari siswa kelas 4 SDIT Buah Hati Pemalang. Berdasarkan hasil pre-test kelas eksperimen terdapat 15 siswa tuntas dalam mencapai batas kriteria ketuntasan minimal (KKM) muatan pelajaran matematika materi operasi hitung pecahan yaitu 70. Dan hasil pre-test kelas kontrol terdapat 18 siswa yang hasil belajarnya tuntas dalam mencapai batas kriteria ketuntasan minimal (KKM) sedangkan terdapat 12 siswa yang hasil belajarnya masih belum tuntas.

Berdasarkan hasil Pre-test kedua sampel antara kelas eksperimen dan kelas kontrol, dihasilkan rata-rata siswa kelas eksperimen yang hasil belajar materi operasi hitung pecahan sudah mencapai KKM sebesar $50 \%$ dan siswa kelas kontrol yang sudah mencapi KKM sebesar $60 \%$. Berdasarkan perhitungan yang sudah dianalisis, maka dapat disimpulkan bahwa kedua sampel berasal dari kemampuan awal yang sama, yakni masih ada beberapa siswa yang hasil belajarnya rendah dan belum mencapai kriteria ketuntasan minimal (KKM). 


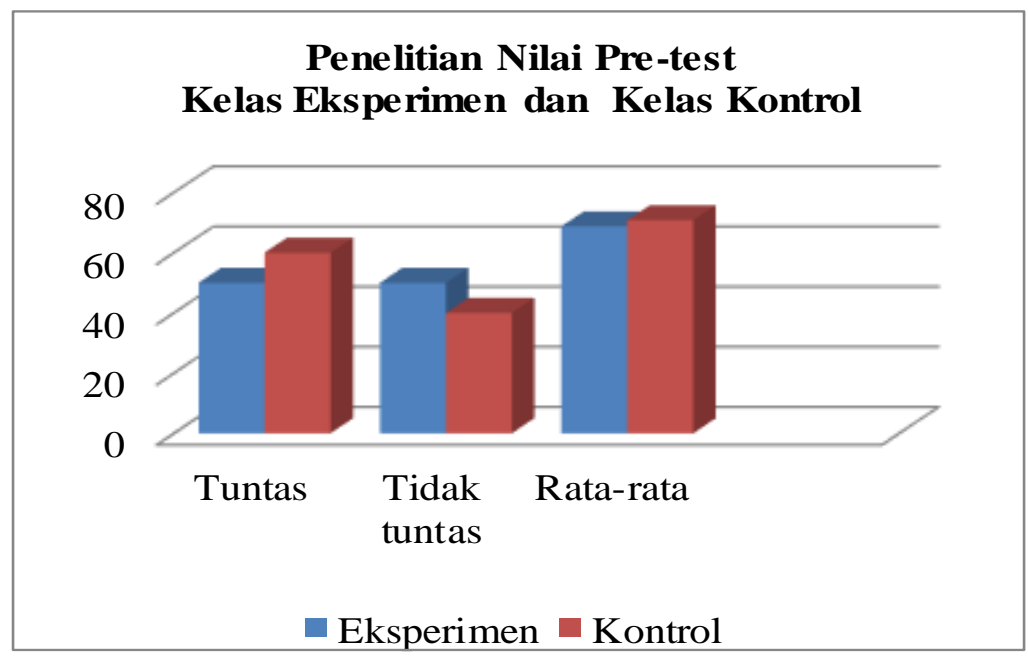

Gambar 1. Nilai Pre-test Kelas Eksperimen dan Kelas Kontrol

Nilai hasil post-test diambil dari hasil soal evaluasi oleh siswa setelah dilaksanakannya pembelajaran dengan menggunakan Metode Everyone Is Teacher Here maupun kelas kontrol dengan pembelajaran konvensional.

Berdasarkan hasil post-test kedua sampel diketahui siswa kelas eksperimen yang hasil belajarnya mencapai batas KKM sebesar 100\%, sedangkan siswa kelas kontrol yang hasil belajarnya mencapai batas KKM sebesar 73,33\%. Selanjutnya dapat disimpulkan bahwa kedua sampel memiliki perbedaan hasil belajar antara yang mendapat perlakuan dengan Metode Everyone Is Teacher Here dengan yang hasil belajar pada kelas yang tidak mendapat perlakuan.

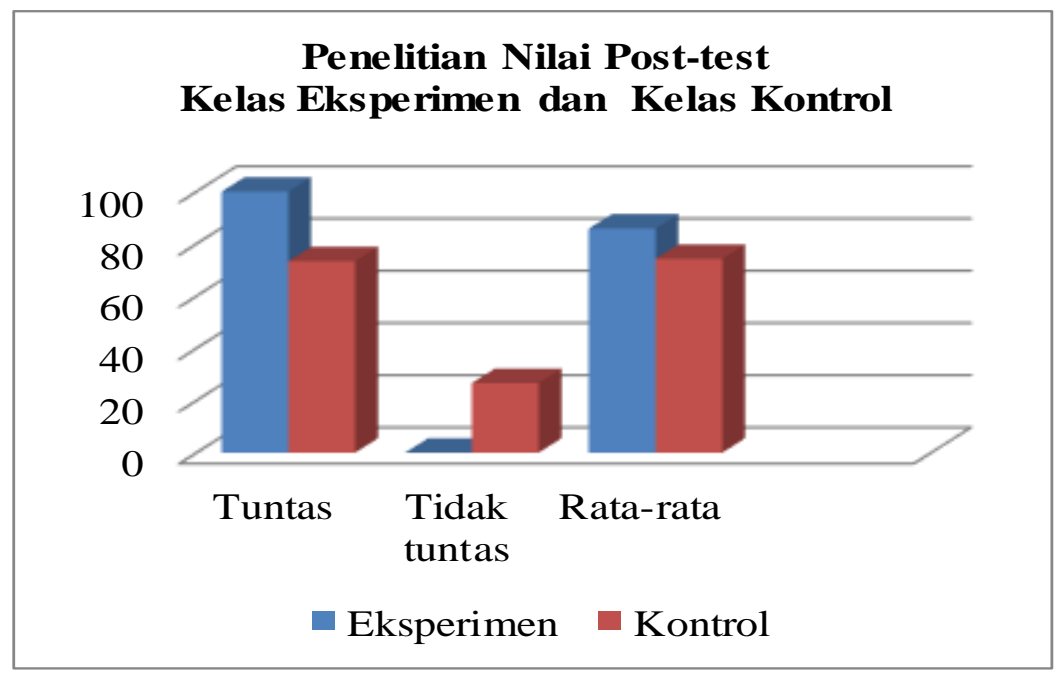

Gambar 2. Nilai Pre-test Kelas Eksperimen dan Kelas Kontrol

Berdasarkan analisis data yang telah diuraikan di atas diketahui bahwa dari uji hipotesis diperoleh bahwa setelah dilakukan pengujian antar dua sampel dengan uji-t disimpulkan bahwa pada hipotesis terdapat pengaruh hasil belajar siswa jika diterapkan pembelajaran tematik dengan menggunakan Metode Everyone Is Teacher Here dengan rata-rata nilai 85,87 karena thitung $>$ ttabel yaitu thitung $=3,993>$ ttabel $=$ 1,671. Hal tersebut berarti Metode Everyone Is Teacher Here memberikan pengaruh yang baik terhadap hasil belajar siswa. 
Berdasarkan hasil perhitungan ketuntasan belajar kelas eksperimen yang tuntas hasil belajarnya yaitu 30 siswa, dengan persentase ketuntasan $100 \%$ dan rata-rata 85,87 . Sedangkan pada kelas kontrol ada 22 siswa yang tuntas hasil belajarnya dengan persentase ketuntasan $73,33 \%$ dan nilai rata-rata 74,27 . Dengan demikian penelitian ini menunjukkan bahwa pembelajaran tematik dengan menggunakan Metode Everyone Is Teacher Here memberikan pengaruh pada hasil belajar siswa menjadi lebih baik dan lebih efektif.

Dengan perbedaan persentase ketuntasan antara kelas eksperimen dan kelas kontrol, perbedaan rata-rata nilai post test kelas eksperimen dan kelas kontrol maka dapat disimpulkan bahwa pembelajaran materi operasi hitung pecahan dengan menggunakan Metode Everyone Is Teacher Here baik digunakan dalam pembelajaran kelas 4 SDIT Buah Hati Pemalang. Berdasarkan analisis data yang telah diuraikan di atas diketahui bahwa dari uji hipotesis diperoleh bahwa setelah dilakukan pengujian antar dua sampel dengan uji-t disimpulkan bahwa pada hipotesis terdapat pengaruh hasil belajar siswa jika diterapkan pembelajaran tematik dengan menggunakan Metode Everyone Is Teacher Here dengan rata-rata nilai 85,87 karena thitung $>$ ttabel yaitu thitung $=3,993>$ ttabel $=1,671$. Hal tersebut berarti Metode Everyone Is Teacher Here memberikan pengaruh yang baik terhadap hasil belajar siswa.

\section{SIMPULAN}

Setelah dilakukan pengujian antar dua sampel dengan uji-t disimpulkan bahwa pada hipotesis terdapat perbedaan peningkatan hasil belajar siswa jika diterapkan pembelajaran dengan menggunakan Metode Everyone Is Teacher Here pada pembelajaran matematika materi operasi hitung pecahan. Dibuktikan dengan rata-rata yang diperoleh 85,87 karena thitung $>$ ttabel yaitu thitung $=3,993>\operatorname{ttabel}=1,671$. Hal tersebut berarti Metode Everyone Is Teacher Here memberikan pengaruh yang sama baik terhadap hasil belajar siswa.

Selanjutnya dapat disimpulkan bahwa Metode Everyone Is Teacher Here efektif digunakan dalam pembelajaran matematika materi operasi hitung pecahan kelas 4 SD. Pengaruh yang signifikan pada Metode Everyone Is Teacher Here terlihat dari persentase ketuntasan hasil post- test siswa yaitu sebanyak 30 siswa, dengan persentase ketuntasan $100 \%$ dengan nilai rata-rata 85,87 telah mencapai kriteria ketuntasan minimal. Sedangkan pada kelas kontrol ada 22 siswa yang tuntas hasil belajarnya dengan persentase ketuntasan $73,33 \%$ dan nilai rata-rata 74,27.

\section{DAFTAR PUSTAKA}

Arikunto, Suharsimi. (2013). Dasar-Dasar Evaluasi Pendidikan. Jakarta: Bumi Aksara. Arikunto,Suharsimi. (2013). Prosedur Penelitian. Jakarta: Rineka Cipta.

Ariyanto. (2011). Pembelajaran Aritmatika Sekolah Dasar. Solobaru:Qinant Hamdani. (2011). Strategi Belajar Mengajar. Bandung:CV Pustaka Setia.

Hardini, Isriani dan Dewi Puspitasari. (2011). Strategi Pembelajaran Terpadu (Teori, Konsep \& Implementasinya). Yogyakarta : Familia (Group Relasi Inti Media).

Kementerian Pendidikan Dan Kebudayaan. 2013. Kurikulum 2013 Kompetensi Dasar Sekolah Dasar (SD/ MI).

Komsiyah, Indah. (2012). Belajar dan Pembelajaran. Yogyakarta: Penerbit Teras Kyriacou, Chris. (2011). Effective Teaching Theory And Practice. Bandung:Nusa Media. 
Mahrani. (2013). Peningkatan Hasil Belajar Matematika Menggunakan Pembelajaran Berbantuan Power Point Kelas VI SDN 27 Pontianak Utara. Pontianak:Universitas Tanjungpura Pontianak.

Sodiq. Siswanto. (2011). Everyone Is Teacher Here. Jakarta: Pariwara Sugiyono. (2012). Metode Penelitian Pendidikan.Bandung: Alfabeta. Suryobroto. (2009). Proses Belajar Mengajar di Sekolah. Jakarta: Rineka Cipta. Uno, Hamzah B. (2011). Perencanaan Pembelajaran. Jakarta: Bumi Aksara.

Zaini, Hisyam. (2012). Strategi Pembelajaran Aktif. Yogyakarta : Pustaka Insan Madani. 